\title{
EVALUATING THE IMPACT OF VITAMIN E SUPPLEMENTATION AS AN ADJUNCT TO PERIODONTAL THERAPY ON LIPID PEROXIDATION IN STAGE II PERIODONTITIS PATIENTS: A RANDOMIZED CONTROLLED TRIAL
}

\author{
Sarah G. Moussa*
}

\begin{abstract}
Objective: Vitamin E has an antioxidant effect and was suggested to induce positive effect when used in periodontitis cases. In periodontitis, malondialdehyde (MDA) is an oxidative stress parameter and a well-established lipid peroxidation (LPO) product that was used to weigh the oxidative damages in periodontitis patients.
\end{abstract}

Aim: The aim of the current study was to assess the effect of systemic usage of vitamin $\mathrm{E}$ as an aide to non-surgical periodontal therapy in treatment of stage II periodontitis patients and evaluate its effect on the MDA levels in gingival crevicular fluid (GCF).

Subjects and method: Thirty patients having stage II periodontitis were included and divided into two groups: Control group only receiving scaling and root planing (SRP) and test group receiving SRP in addition systemic administration of vitamin E 400mg every other day. Clinical parameters Gingival Index (GI), Plaque Index (PI), Probing Depth (PD) and Clinical Attachment Level (CAL)) were recorded and GCF samples to assess the MDA level were collected at baseline and at 8 weeks follow up.

Results: At follow up, both groups exhibited statistically significant changes in all clinical parameters without any significant differences between the two groups. Reduction in MDA was significant in control and test groups at the 8 weeks follow up. However, it was more significant in the test group.

Conclusion: The adjunctive use of systemic vitamin $\mathrm{E}$ in periodontal therapy have showed to be effective in reducing the lipid peroxidation in stage II periodontitis patients. However, the clinical profit of its use is questionable.

KEY WORDS: Antioxidants (AOs), Vitamin E, lipid peroxidation (LPO), malondialdehyde (MDA), Gingival crevicular fluid (GCF).

\footnotetext{
* Lecturer at Department of Oral Medicine, Periodontology and Diagnosis, Future University in Egypt, Cairo, Egypt.
} 


\section{INTRODUCTION}

Periodontitis is a chronic inflammatory disease which affects the tooth-supporting tissues, such as the periodontal ligament, alveolar bone, and gingiva, and it is not initiated by a solitary or even limited organisms but relatively by polymicrobial groups of indigenous microbes acting in concert ${ }^{(1,2)}$. Periodontal disease arises when the balance between the host immune response and pathogens is disturbed ${ }^{(3)}$. Recently, reactive oxygen species (ROS) have grew more consideration because of their vital role in the evolution of several inflammatory diseases ${ }^{(4)}$. However, ROS do not differentiate between host tissues and pathogens, and hence, tissue injury can ascend from excessive plaque-induced extracellular ROS release. ROS are stated to contribute to the progression of periodontitis via direct and indirect mechanisms, counting DNA strand breaking ${ }^{(5)}$, tissue destruction ${ }^{(6,7)}$, amplified osteoclast differentiation ${ }^{(8)}$, lipid peroxidation (LPO) ${ }^{(9)}$, and commencement of a self-perpetuating series that stimulates chronic immune cell-derived ROS production ${ }^{(10)}$.

On the other hand, antioxidants (AOs) are another type of substances that are normally found in the cells and can efficiently postpone or prevent ROS-induced oxidation. Under physiological circumstances, AOs effectively neutralize ROS and prevents ROS- mediated tissue destruction. Once inflammation occurs, ROS production is severely amplified and the AO defense system cannot balance it, leading to the oxidative stress and tissue damage ${ }^{(4,11)}$.

Vitamin E refers to a group of eight natural composites consisting of numerous tocotrienols (TCTs) and tocopherols (TOCs) and is considered as the most significant oil-soluble antioxidant found in nature ${ }^{(12,13)}$. In addition, vitamin $\mathrm{E}$ is the initial line of defense against lipid peroxidation by defending cell membranes throughout the early phases of free radical attack ${ }^{(14)}$. Vitamin $\mathrm{E}$ was shown to play a significant role in preventing destruction of the alveolar bone and reducing the periodontal inflammation by acting as a prostaglandin inhibitor ${ }^{(15,16)}$.

Lipid peroxidation is one of the most significant reactions of free radicals (FR) species that results in the changes of the function and structural integrity of cell membranes. Numerous lipid peroxidation products such as malondialdehyde (MDA), isoprostane and 4-hydroxy-nonenal (HNE) have been used to assess both systemic and local oxidative damages linked with periodontitis ${ }^{(4)}$. MDA is a guideline of oxidative stress and is a well-established LPO product that is used to govern the level of cell membrane damage, and it is also the most investigated product of lipid peroxidation in periodontitis ${ }^{(17) .}$ Higher MDA levels were significantly found in gingival tissues and GCF of periodontitis patients contrasted to periodontal healthy controls ${ }^{(18)}$. Furthermore, a study by Ghallab et al. 2015 showed that MDA levels in GCF can differentiate between aggressive periodontitis, chronic periodontitis, and periodontally healthy controls ${ }^{(19)}$.

To our knowledge, we found no human study that estimated the effect of vitamin $\mathrm{E}$ on MDA levels in periodontitis patients. Therefore, the aim of the present study was to assess the outcome of systemic use of vitamin $\mathrm{E}$ in adjunction with nonsurgical periodontal therapy for treatment of stage II periodontitis patients.

\section{Subjects and methods}

This controlled double-blinded, randomized study was carried out on thirty non-smoking stage II periodontitis patients ( 9 men, 21 women) from the outpatients' clinic in Faculty of Oral and Dental Medicine, Future university in Egypt.

\section{The patients were selected according to the fol- lowing criteria:}

- Patients' age range from 22-50 years.

- Medically free patients according to the modified Cornell Medical Index ${ }^{(20)}$. 
- $\quad$ Stage II periodontitis patients having at least 20 natural teeth with interdental CAL detectable at $\geq 2$ nonadjacent teeth, or buccal or oral CAL $\geq 3 \mathrm{~mm}$ with pocketing $>3 \mathrm{~mm}$ detectable at $\geq 2$ teeth and CAL 3-4 $\mathrm{mm}$ and maximum PD $\leq 5$ $\mathrm{mm}^{(21)}$

\section{The criteria for exclusion were as follows}

- Patients with known or suspected allergy to vitamin E.

- Patients who had any type of periodontal treatment in the past 6 months preceding to examination.

- Users of tobacco in any form \& alcoholics.

- Patients who used anti-inflammatory or antibiotic or antioxidants drugs within the 6 months former to the beginning of the study,

- Pregnant or lactating females.

\section{Study design}

All selected patients were motivated about the benefit of the periodontal treatment. They received detailed instruction about the purpose of the study, steps, and expected benefits or risks that may arise. At baseline, proper case history, clinical examination and radiographic evaluation were done to selected subjects. Collection of the GCF samples was done before treatment at the beginning of the study and at 8 weeks follow up.

After GCF collection, thorough scaling and root planing (SRP) was performed for all patients using both ultrasonic (Various 350, NSK, Japan) and standard Gracey periodontal curettes (Hu-Fridey instruments, Chicago, IL, USA) for meticulous elimination of subgingival and supragingival plaque and calculus.

Thirty patients were randomly divided into two groups:

- Control group: 15 patients received only SRP.

- Test group: 15 patients received SRP in addition to vitamin E (Pharco pharmaceuticals®, Egypt) $400 \mathrm{mg}$ every other day for 8 weeks.

\section{Clinical evaluation}

The subsequent periodontal parameters were recorded at baseline and after 8 weeks:

- Gingival Index (GI): the status of the gingiva was evaluated to assess gingival inflammation absence or presence (22).

- Plaque Index (PI): the sum of dental plaque was evaluated in order to screen the patient's oral hygiene performance (23).

- Probing Pocket Depth (PPD): the span between the gingival margin and the base of the pocket and was measured via William's graduated periodontal probe.

- Clinical Attachment Level (CAL): was measured from the CEJ to the base of the pocket using William's graduated periodontal probe.

\section{Collection of GCF samples:}

GCF samples were obtained from the deepest PD sites at baseline and 8 weeks follow up. GCF samples were collected as follows: All supragingival plaque was detached and all blood spots or debris were removed from the tooth surfaces and then became air dried and cotton rolls were used to isolate the tooth surface from saliva. Sterile periopaper strip $(1.5 \times 20 \mathrm{~mm})$ was inserted into the pocket until slight resistance was felt and kept in place for 30 seconds. contaminated Strips were discarded. Subsequent to GCF collection, the strips were immediately placed in sterile Eppendorf tubes and then were kept in liquid nitrogen $\left(-80^{\circ} \mathrm{C}\right)$ until biochemical analysis (24). Evaluation of changes in the GCF level of MDA was done using enzymelinked immunosorbent assay (ELISA).

\section{Statistical analysis}

Data were analyzed using SPSS version 21. The data normality was first tested with Shapiro 
test. Continuous variables were shown as mean \pm SD (standard deviation). $t$ test was used groups to compare the two groups, while paired groups were compared by paired t-test. The threshold of significance is fixed at $5 \%$ level (P-value).

\section{RESULTS}

Thirty patients (21 females -9 males) with age ranging from 25 to 49 years old and mean age of $32.53( \pm 6.40)$ were included in the present study and continued the 8 weeks follow up evaluation. The patients who received vitamin E reported no adverse side effects.

Post-treatment changes in control and test groups showed a statistically significant reduction in MDA and all clinical parameters (Table 1). At 8 weeks follow up, the PI, GI, PD and CAL readings were reduced in the test group compared to the control group, however this difference was not statistically significant. In contrast, there was a statistically significant difference in the MDA readings at 8 weeks follow up in the favor of the test group (Table 2).

TABLE (1): Effect of post-operative duration time on the mean change on all clinical variables during the follow-up period within each group.

\begin{tabular}{lccccc}
\hline & PI & GI & PD & CAL & MDA \\
\hline Control & $\mathbf{1 . 1 3} \pm \mathbf{0 . 0 9 1}$ & $\mathbf{0 . 8 0} \pm \mathbf{0 . 1 0 7}$ & $\mathbf{1 . 0 7} \pm \mathbf{0 . 1 5}$ & $\mathbf{0 . 8 7} \pm \mathbf{0 . 1 6}$ & $\mathbf{0 . 7 9 5} \pm \mathbf{0 . 0 6}$ \\
BL-8 weeks & $P<0.0001^{*}$ & $P<0.0001^{*}$ & $P<0.0001^{*}$ & $P<0.0001^{*}$ & $P<0.0001^{*}$ \\
\hline Test & $\mathbf{1 . 4 0} \pm \mathbf{0 . 1 6}$ & $\mathbf{1 . 2 7} \pm \mathbf{0 . 1 8}$ & $\mathbf{1 . 8 0} \pm \mathbf{0 . 2}$ & $\mathbf{1 . 8 0} \pm \mathbf{0 . 1 7}$ & $\mathbf{0 . 9 2 9} \pm \mathbf{0 . 0 7}$ \\
BL-8 weeks & $P<0.0001^{*}$ & $P<0.0001^{*}$ & $P<0.0001^{*}$ & $P<0.0001^{*}$ & $P<0.0001^{*}$ \\
\hline
\end{tabular}

*: significant at $P \leq 0.05$

TABLE (2): Comparison of the Mean and standard deviation values in all clinical variables between test and control patients at baseline and at 2 months follow up.

\begin{tabular}{|c|c|c|c|c|}
\hline & Control & Test & T-value & P-value \\
\hline \multicolumn{5}{|l|}{ Plaque index (PI) } \\
\hline Baseline & $1.87 \pm 0.64$ & $2.00 \pm 0.93$ & 0.4588 & 0.6499 \\
\hline 8 weeks follow up & $0.73 \pm 0.70$ & $0.60 \pm 0.51$ & 0.5953 & 0.5564 \\
\hline \multicolumn{5}{|l|}{ GingivaI index (GI) } \\
\hline Baseline & $1.53 \pm 0.83$ & $1.60 \pm 0.91$ & 0.2092 & 0.8358 \\
\hline 8 weeks follow up & $0.73 \pm 0.70$ & $0.33 \pm 0.49$ & 1.8091 & 0.0812 \\
\hline \multicolumn{5}{|c|}{ Probing depth (PD) } \\
\hline Baseline & $5.20 \pm 1.21$ & $5.71 \pm 0.99$ & 1.2470 & 0.2231 \\
\hline 8 weeks follow up & $4.13 \pm 1.13$ & $3.73 \pm 0.96$ & 1.0467 & 0.3042 \\
\hline \multicolumn{5}{|c|}{ Clinical Attachment Level (CAL) } \\
\hline Baseline & $5.13 \pm 1.51$ & $5.53 \pm 1.60$ & 0.7057 & 0.4862 \\
\hline 8 weeks follow up & $4.27 \pm 1.28$ & $3.73 \pm 1.16$ & 1.1945 & 0.2423 \\
\hline \multicolumn{5}{|l|}{ MDA } \\
\hline Baseline & $1.889 \pm 0.28$ & $1.762 \pm 0.36$ & 1.0663 & 0.2954 \\
\hline 8 weeks follow up & $1.094 \pm 0.25$ & $0.834 \pm 0.20$ & 3.0486 & $0.0050^{*}$ \\
\hline
\end{tabular}

*: significant at $P \leq 0.05$ 


\section{DISCUSSION}

Mechanical elimination of subgingival plaque and root surface debridement have been known as the gold standard approach to control periodontal diseases ${ }^{(25)}$. Yet, in many cases only scaling and root debridement is not enough to control the disease and maintain the periodontal health. Adjunctive consumption of micronutrients such as vitamins in periodontal therapy has been anticipated to help sustaining a stable immune system via affecting numerous host response biological processes and enhancing the innate immune system ${ }^{26,27)}$.

An oxidant-antioxidant balance is usually present in the healthy human body, and when this balance is disturbed and shifted to the oxidant side, oxidative stress occurs. Oxidative stress was found to be linked to various systemic diseases and conditions such as diabetes ${ }^{(28)}$, ulcerative colitis ${ }^{(29)}$, rheumatoid arthritis ${ }^{(30)}$ and oral lichen planus ${ }^{(31)}$.

Vitamin $\mathrm{E}$ is an antioxidant fat-soluble agent that normally presents in all cell membranes to inhibit the oxidative damage in membrane lipids ${ }^{(32)}$. The suggested dose of vitamin $\mathrm{E}$ as a routine nutritional supplement for adults is 200 to 400 IU once daily. A 300-IU preparation for everyday supplementation was not available, so patients in the test group received a dose of $400 \mathrm{mg}$ (596 IU) vitamin E on alternate days for the 8 weeks observation period. This alternate day regime of vitamin $E$ intake was used in some studies without any untoward response ${ }^{(34,35)}$.

Owing to the antioxidant effect of vitamin E, the current study was hence planned to assess the outcome of systemically delivered vitamin $\mathrm{E}$ in addition to the nonsurgical periodontal therapy on the clinical parameters (GI, PI, PD, and CAL) as well as MDA levels in the GCF of stage II periodontitis patients.

Both groups displayed significant improvement in all clinical parameters after 8 weeks follow up period. The results of the present study question the beneficial effect of systemic delivery of vitamin $\mathrm{E}$ on the periodontal disease, and this was reflected by the non-significant differences between control and test groups in all clinical parameters at the 8 weeks follow up.

Comparable results were conducted by Hong et al (2019) who evaluated the gingival inflammation from fixed-dose mixtures of vitamin $\mathrm{C}$, vitamin $\mathrm{E}$, lysozyme and carbazochrome (CELC) as an adjunctive to scaling and root planing in the treatment of chronic periodontitis cases ${ }^{(36)}$. In their study, CELC group displayed a significant reduction in gingival inflammation parameter only compared to the control. Other parameters (PI, PD and CAL), however, were similar between both groups.

On the other hand, Singh et al., (2014) demonstrated that the test group that received 200 $\mathrm{mg}$ (300 IU) vitamin E every other day in addition to SRP showed a significant improvement in all periodontal parameters when compared to the group that received only SRP at 3 months follow up. They mentioned that adjunctive vitamin E may have played a supplementary role in resolution of the periodontal inflammatory problem ${ }^{(33)}$.

Malondialdehyde (MDA), is one of the final disintegration products of lipid peroxidation (LPO) and is an indicator of the associated deleterious effects on biological systems ${ }^{(37)}$. In addition, MDA can act as an oxidative stress biomarker in chronic inflammatory diseases (8). MDA levels were assessed in serum, saliva, and GCF of chronic periodontitis patients, and in two studies it was found that periodontitis had no effect on systemic MDA levels, unlike local MDA levels that were raised in periodontitis patients ${ }^{(38,39)}$. Hence in this study, MDA levels were measured in the GCF not in the serum.

The results obtained from the present study showed a significant decrease in the MDA level following SRP in both control and test groups at the 8 weeks follow up. These results go in accordance with Wei et al., 2010 who mentioned that nonsurgical therapy can restore the antioxidant capacity by systemically and locally adjusting the levels of 
MDA, total oxidative status (TOS) and superoxide dismutase (SOD) ${ }^{(39)}$. In addition, Guentsch et al., 2008 in their study assessed the effect of smoking and periodontal treatment on LPO and the equivalent antioxidant activity in periodontitis patients and concluded that non-surgical periodontal treatment aids in reducing the MDA to levels comparable to healthy controls ${ }^{(40)}$.

After 8 weeks, MDA levels were significantly reduced in the test group in comparison with the control group recommending the positive effect the systemic administration of vitamin $\mathrm{E}$ in addition to SRP. Esenlik et al., (2012) investigated the effect of vitamin $\mathrm{E}$ on the levels of MDA in patients with orthodontic tooth movement. They found that vitamin E supplementation reduced the MDA level in the anterior region following orthodontic tooth movement which reflects the protective role of vitamin E on LPO levels ${ }^{(41)}$.

In conclusion, vitamin $\mathrm{E}$ is a free-radical scavenger that helps in inhibiting LPO in addition to SRP in stage II periodontitis patients. The effect of vitamin $\mathrm{E}$ on the clinical parameters though is questionable. Further investigations on a larger scale of patients are required to confirm the positive effect of vitamin E administration the stage II periodontitis patients.

\section{REFERENCES}

1. Yang Y, Huang Y, Li W. Autophagy and its significance in periodontal disease. J Periodontal Res [Internet]. 2021 Jan 1 [cited 2021 Aug 5];56(1):18-26.

2. Hajishengallis G, Lamont RJ. Polymicrobial communities in periodontal disease: Their quasi-organismal nature and dialogue with the host. Periodontol 2000 [Internet]. 2021 Jun 1 [cited 2021 Aug 5];86(1):210-30.

3. SILVA N, ABUSLEME L, BRAVO D, DUTZAN N, GARCIA-SESNICH J, VERNAL R, et al. Host response mechanisms in periodontal diseases. J Appl Oral Sci [Internet]. 2015 Jul 28 [cited 2021 Aug 5];23(3):329-55.

4. Khan S, Kumar S, Iqbal S, MT J, Ramaprabha G. Oxidative stress, antioxidants, and periodontitis: How are they linked. Int J Oral Care Res [Internet]. 2018 [cited 2021 Aug 7];6(2):107-12.
5. Dix TA, Hess KM, Medina MA, Sullivan RW, Tilly SL, Webb TLL. Mechanism of site-selective DNA nicking by the hydrodioxyl (perhydroxyl) radical. Biochemistry. 1996 Apr 9;35(14):4578-83.

6. Sharma A, clinics SS-I journal of D, 2011 undefined. Reactive oxygen species and antioxidants in periodontics: a review. intjdc.org [Internet]. [cited $2021 \mathrm{Aug} 7$ ];

7. Chappie ILC. Role of free radicals and antioxidants in the pathogenesis of the inflammatory periodontal diseases. $\mathrm{J}$ Clin Pathol - Clin Mol Pathol. 1996;49(5).

8. Waddington RJ, Moseley R, Embery G. Reactive oxygen species: A potential role in the pathogenesis of periodontal diseases. Oral Dis [Internet]. 2000 [cited 2021 Aug 7];6(3):138-51.

9. Dix TA, Aikens J. Mechanisms and Biological Relevance of Lipid Peroxidation Initiation. Chem Res Toxicol. 1993;6(1):2-18.

10. Dahiya P, Kamal R, Gupta R, Bhardwaj R, Chaudhary K, Kaur S. Reactive oxygen species in periodontitis. J Indian Soc Periodontol. 2013 Jul;17(4):411-6.

11. Wang Y, Andrukhov O, Rausch-Fan X. Oxidative stress and antioxidant system in periodontitis. Front Physiol. 2017 Nov 13;8(NOV).

12. Brigelius-Flohé R, Traber MG. Vitamin E: function and metabolism. FASEB J [Internet]. 1999 Jul [cited 2021 Aug 8];13(10):1145-55.

13. 13. SR M. Prospects for the use of antioxidant therapies. Drugs [Internet]. 1995 [cited 2021 Aug 8];49(3):345-61.

14. Horwitt MK. Interpretations of requirements for thiamin, riboflavin, niacin-tryptophan, and vitamin E plus comments on balance studies and vitamin B-6. Am J Clin Nutr [Internet]. 1986 Dec 1 [cited 2021 Aug 8];44(6):973-85.

15. Cohen ME, Meyer DM. Effect of dietary vitamin E supplementation and rotational stress on alveolar bone loss in rice rats. Arch Oral Biol. 1993 Jul 1;38(7):601-6.

16. Chapple ILC. Role of free radicals and antioxidants in the pathogenesis of the inflammatory periodontal diseases. Clin Mol Pathol [Internet]. 1996 [cited 2021 Aug 8]; 49(5):M247.

17. Ahmadi-Motamayel F, Goodarzi MT, Jamshidi Z, Kebriaei R. Evaluation of salivary and serum antioxidant and oxidative stress statuses in patients with chronic periodontitis: A case-control study. Front Physiol. 2017 Mar 31;8(MAR). 
18. Tonguc ztürk, Sütc xü R, Mermi Ceyhan B, Kılınc G, Sönmez Y, Yetkin Ay Z, et al. The impact of smoking status on antioxidant enzyme activity and malondialdehyde levels in chronic periodontitis. Wiley Online Libr [Internet]. 2011 Sep [cited 2021 Aug 9];82(9):1320-8.

19. Ghallab N, Hamdy E, journal OS-A dental, 2016 undefined. Malondialdehyde, superoxide dismutase and melatonin levels in gingival crevicular fluid of aggressive and chronic periodontitis patients. Wiley Online Libr [Internet]. 2015 Mar 1 [cited 2021 Aug 9];61(1):53-61.

20. Brodman K, Erdmann A, Association IL-... M, 1951 undefined. The Cornell medical index-health questionnaire: II. As a diagnostic instrument. jamanetwork.com [Internet]. [cited 2021 Mar 31];

21. Tonetti MS, Greenwell H, Kornman KS. Staging and grading of periodontitis: Framework and proposal of a new classification and case definition. J Periodontol. 2018 Jun 1;89:S159-72.

22. Löe H, Silness J. Periodontal disease in pregnancy I. Prevalence and severity. Acta Odontol Scand. 1963;21(6):533-51.

23. Silness J, Löe H. Periodontal disease in pregnancy II. Correlation between oral hygiene and periodontal condition. Acta Odontol Scand. 1964;22(1):121-35.

24. Alev Akalın F, Baltacıog E, Alver A, Karabulut E. Total Antioxidant Capacity and Superoxide Dismutase Activity Levels in Serum and Gingival Crevicular Fluid in Pregnant Women With Chronic Periodontitis; Total Antioxidant Capacity and Superoxide Dismutase Activity Levels in Serum and Gingival Crevicular Fluid in Pregnant Women With Chronic Periodontitis. J Periodontol [Internet]. 2009 Mar [cited 2021 Jun 10];80(3):457-67.

25. Cobb CM, Jeffcoat. Clinical significance of non-surgical periodontal therapy: An evidence-based perspective of scaling and root planing. J Clin Periodontol. 2002; 29(SUPPL. 2):22-32.

26. Velden U Van der, periodontology DK-... clinical, 2011 undefined. Micronutritional approaches to periodontal therapy. Wiley Online Libr [Internet]. 2011 Mar [cited 2021 Oct 13];38(SUPPL. 11):142-58.

27. Dawson DR, Branch-Mays G, Gonzalez OA, Ebersole JL. Dietary modulation of the inflammatory cascade. Periodontol 2000 [Internet]. 2014 Feb 1 [cited 2021 Oct 13]; 64(1):161-97.
28. Asmat U, Abad K, Ismail K. Diabetes mellitus and oxidative stress - A concise review. Saudi Pharm J. 2016 Sep 1;24(5):547-53.

29. Tahan G, Aytac E, Aytekin H, Gunduz F, Dogusoy G, Aydin $\mathrm{S}$, et al. Vitamin $\mathrm{E}$ has a dual effect of anti-inflammatory and antioxidant activities in acetic acid-induced ulcerative colitis in rats. Can J Surg [Internet]. 2011 [cited 2021 Oct 15]; 54(5):333.

30. Navarro-Compán V, Melguizo-Madrid E, Hernández-Cruz B, Santos-Rey K, Leyva-Prado C, González-Martín C, et al. Interaction between oxidative stress and smoking is associated with an increased risk of rheumatoid arthritis: a case-control study. Rheumatology [Internet]. 2013 Mar 1 [cited 2021 Oct 15];52(3):487-93.

31. Rai B, Kharb S, Jain R, Anand SC. Salivary Vitamin E and $\mathrm{C}$ in Lichen Planus. Gomal J Med Sci [Internet]. 2008 [cited 2021 Oct 15];6(2).

32. Chapple I, 2000 JM-P, 2007 undefined. The role of reactive oxygen and antioxidant species in periodontal tissue destruction. researchgate.net [Internet]. 2000 [cited 2021 Oct 15];43:160-232.

33. Singh N, Narula SC, Sharma RK, Tewari S, Sehgal PK. Vitamin E Supplementation, Superoxide Dismutase Status, and Outcome of Scaling and Root Planing in Patients With Chronic Periodontitis: A Randomized Clinical Trial. J Periodontol [Internet]. 2014 Feb 1 [cited 2021 Oct 22];85(2):242-9.

34. Sesso HD, Buring JE, Christen WG, Kurth T, Belanger C, MacFadyen J, et al. Vitamins E and C in the Prevention of Cardiovascular Disease in Men: The Physicians' Health Study II Randomized Controlled Trial. JAMA [Internet]. 2008 Nov 12 [cited 2021 Oct 23];300(18):2123-33.

35. Lee I-M, Cook NR, Gaziano JM, Gordon D, Ridker PM, Manson JE, et al. Vitamin E in the Primary Prevention of Cardiovascular Disease and Cancer: The Women's Health Study: A Randomized Controlled Trial. JAMA [Internet]. 2005 Jul 6 [cited 2021 Oct 23];294(1):56-65

36. Hong J-Y, Lee J-S, Choi S-H, Shin H-S, Park J-C, Shin $\mathrm{S}-\mathrm{I}$, et al. A randomized, double-blind, placebo-controlled multicenter study for evaluating the effects of fixeddose combinations of vitamin $\mathrm{C}$, vitamin $\mathrm{E}$, lysozyme, and carbazochrome on gingival inflammation in chronic periodontitis patients. BMC Oral Heal 2019191 [Internet]. 2019 Mar 7 [cited 2021 Oct 24];19(1):1-8.

37. Sies H. Oxidative stress: Oxidants and antioxidants. Exp Physiol. 1997;82(2):291-5. 
38. Akalın FA, Baltacıoğlu E, Alver A, Karabulut E. Lipid peroxidation levels and total oxidant status in serum, saliva and gingival crevicular fluid in patients with chronic periodontitis. J Clin Periodontol [Internet]. 2007 Jul 1 [cited 2021 Oct 29];34(7):558-65.

39. Wei D, Zhang X-L, Wang Y-Z, Yang C-X, Chen G. Lipid peroxidation levels, total oxidant status and superoxide dismutase in serum, saliva and gingival crevicular fluid in chronic periodontitis patients before and after periodontal therapy. Aust Dent J [Internet]. 2010 Mar 1 [cited 2021 Oct 29];55(1):70-8.
40. Guentsch A, Preshaw PM, Bremer-Streck S, Klinger G, Glockmann E, Sigusch BW. Lipid peroxidation and antioxidant activity in saliva of periodontitis patients: effect of smoking and periodontal treatment. Clin Oral Investig 2008124 [Internet]. 2008 May 29 [cited 2021 Oct 29];12(4):345-52.

41. Esenlik E, Nazıroğlu M, Açıkalın C, Övey IS. Vitamin E supplementation modulates gingival crevicular fluid lipid peroxidation and antioxidant levels in patients with orthodontic tooth movement. Cell Biochem Funct [Internet]. 2012 Jul 1 [cited 2021 Oct 30];30(5):376-81. 